\title{
ANÁLISE DA PERTINÊNCIA JURÍDICA DO PROGRAMA ESCOLA SEM PARTIDO COM BASE NO CRITÉRIO DA PROPORCIONALIDADE E NOS CONTROLES DE EVIDÊNCIA E JUSTIFICABILIDADE APLICADOS PELO SUPREMO TRIBUNAL FEDERAL
}

\section{REVIEM OF LEGAL RELEVANCE PROGRAM SCHOOL NO POLITICAL PARTY BASED ON THE PROPORTIONALITY AND EVIDENCE AND JUSTIFIABILITY CONTROLS APPLIED BY THE BRAZILIAN SUPREME COURT}

Grazielly Alessandra Baggenstoss ${ }^{1}$

\section{RESUMO}

Esta pesquisa objetiva examinar o panorama jurídico de propositura do Programa Escola Sem Partido - ESP, que visa a inclusão de dispositivos legais na Lei de Diretrizes e Bases da Educação Nacional (Lei 9.394/1996). Para isso, é problema da pesquisa o questionamento se o mencionado projeto de lei apresenta pertinência jurídica ao ordenamento jurídico brasileiro, bem como ao contexto pedagógico pátrio atual. Dessa forma, com método dedutivo, analisa-se a questão a partir do critério de proporcionalidade de Robert Alexy e dos Controles de Evidência e Justificabilidade aplicados pelo Supremo Tribunal Federal.

Palavras-chave: Critério da Proporcionalidade; Escola Sem Partido; Controles de Evidência e Justificabilidade; Supremo Tribunal Federal; Educação

\begin{abstract}
This research examines the legal context of bringing the School No Political Party Program, which aims to include legal provisions in the Law of Guidelines and Bases of National Education. Therefore, the problem of research is if the mentioned project has legal relevance to the Brazilian legal system, as well as the current pedagogical context. Thus, with deductive method, the question is examined from the proportionality test of Robert Alexy and Evidence and Justifiability Controls, applied by the Brazilian Court.
\end{abstract}

Keywords: Proportionality; School No Political Party Program; Evidence and Justifiability Controls; Court Supreme; Education

\footnotetext{
${ }^{1}$ Doutora e Mestra em Direito Universidade Federal de Santa Catarina - UFSC, (Brasil). Professora de Direito - UFSC e Coordenadora do Grupo de Pesquisa "Modelagem e Compreensão dos Sistemas Sociais: Direito, Estado, Sociedade e Política". E-mail: grazyab@gmail.com
} 


\section{INTRODUÇÃO}

O presente trabalho tem como objetivo analisar o panorama jurídico de propositura do Programa Escola Sem Partido - ESP, questionando-se, como problema, sobre a pertinência jurídica de tal proposta que pretende incluir dispositivos legais na Lei de Diretrizes e Bases da Educação Nacional (Lei 9.394/1996)². Assim, a pertinência jurídica perquirida diz respeito à eventual adequação do conjunto normativo proposto face ao ordenamento jurídico pátrio, bem como à verificação de robustez dos argumentos que fundamentam o projeto de lei, constantes em sua Justificativa e na fala do principal elaborador do projeto, Miguel Nagib, em entrevista concedida ao Canal Futura.

A partir de método dedutivo, portanto, explana-se brevemente sobre a estrutura normativa a qual está inserida a atividade docente no Brasil e acerca de algumas abordagens de ensino para, após, proceder-se a um exame objetivo do Programa ESP. Em seguida, perquire-se sobre as concepções jurídicas trazidas pela proposta de inovação legislativa e, finalmente, explana-se sobre a mencionada pertinência do Programa ESP, com a verificação da imprescindibilidade e da motivação do projeto de lei, inspirada no critério de proporcionalidade de Robert Alexy e nos controles de evidência e de justificabilidade aplicados pelo Supremo Tribunal Federal.

\section{CONSIDERAÇÕES GERAIS SOBRE A ESTRUTURA NORMATIVA BRASILEIRA $^{3}$ RELACIONADA À ATIVIDADE DOCENTE E PERSPECTIVAS PEDAGÓGICAS}

A educação, tal como direito fundamental de cunho social, está previsto no art. $6^{\circ}$ da Constituição Federal e especificado nos seguintes artigos 205 e 206:

\footnotetext{
${ }^{2}$ O referido programa está delineado, em âmbito nacional, pelo Projeto de Lei do Senado no 193/2016, de autoria do senador Magno Malta (PR-ES); pelo Projeto de Lei ${ }^{\circ}$ 867/2015, proposto pelo Deputado Federal Izalci (PSDB/DF). A formulação do conteúdo principal (deveres dos professores) foi formulado pelo advogado Miguel Nagib (Cf. site <http:www.escolasempartido.org>). Destaca-se que é desnecessária a propositura de repetidas propostas nas duas casas do Congresso Nacional, considerando que sua análise gerará, se aprovada, eficácia em seara nacional. Além disso, o Programa também foi proposto em diversas Assembleias Legislativas e em Câmaras de Vereadores. Sobre tais propostas, que pretendam modificar a Lei de Diretrizes e Bases da Educação, apresentam vícios eventuais propostas apresentadas em âmbitos estadual e municipal, pois as Assembleias Legislativas e as Câmaras de Vereadores não possuem atribuição constitucional para alterar uma lei federal.

${ }^{3}$ A breve abordagem é realizada, sem prejuízo de outros ensinos, restritivamente ao ensino superior, considerando a abrangência do Programa ESP.
} 
Art. 205. A educação, direito de todos e dever do Estado e da família, será promovida e incentivada com a colaboração da sociedade, visando ao pleno desenvolvimento da pessoa, seu preparo para o exercício da cidadania e sua qualificação para o trabalho.

Art. 206. O ensino será ministrado com base nos seguintes princípios:

I - igualdade de condições para o acesso e permanência na escola;

II - liberdade de aprender, ensinar, pesquisar e divulgar o pensamento, a arte e o saber;

III - pluralismo de ideias e de concepções pedagógicas, e coexistência de instituições públicas e privadas de ensino;

IV - gratuidade do ensino público em estabelecimentos oficiais;

V - valorização dos profissionais da educação escolar, garantidos, na forma da lei, planos de carreira, com ingresso exclusivamente por concurso público de provas e títulos, aos das redes públicas;

VI - gestão democrática do ensino público, na forma da lei;

VII - garantia de padrão de qualidade.

VIII - piso salarial profissional nacional para os profissionais da educação escolar pública, nos termos de lei federal.

Pela leitura dos dispositivos constitucionais, vê-se que a educação está diretamente alinhada à atividade de ensino, exercida pelo professor. Nesses termos, fala-se em liberdade de cátedra, ou liberdade de ensinar, em cuja atuação o professor possui discricionariedade, representada por um espaço restrito, balizado pela própria lei, que protege o direito de aprender, e pelas diretrizes nacionais do ensino e, especificamente, do curso ministrado. Tal discricionariedade permite que o ensino perpasse por diversas questões, inclusive políticas, de gênero e de orientação sexual, em proteção à previsão de igualdade entre todos ${ }^{4}$.

Nessa tônica, a liberdade de ensinar garante (a) o pluralismo de ideias e concepções no âmbito do processo de ensino e (b) a autonomia didático-científica dos professores.

A prática da docência, como qualquer outra profissão regulamentada, deve seguir diretrizes dispostas em várias instâncias, quais sejam no Estado, nas instituições de ensino, nas regulamentações dos cursos e, também, nas diretrizes traçadas pelo próprio professor .

\footnotetext{
${ }^{4}$ Cf. Plano Nacional de Educação (PNE), Lei no $13.005 / 2014$; e Plano Nacional de Educação em Direitos Humanos, elaborado por Comitê composto pela Secretaria Especial dos Direitos Humanos, Ministério da Educação e Ministério da Justiça, UNESCO e representantes da Sociedade Civil.
} 
Ao Estado, compete estabelecer as normas gerais de educação e estruturar seus sistemas de ensino, de forma a cumprir seu papel no campo específico da educação. Tais normas gerais são consubstanciadas, principalmente:

a) pela Constituição Federal, que estabelece a gestão democrática do ensino público: enfoque na qualidade do ensino, sem qualquer tipo de distinção de 'ideologias', do "pluralismo de ideias e de concepções pedagógicas, e coexistência de instituições públicas e privadas de ensino" (artigo 206, inciso III).

b) pela Lei de Diretrizes e Bases da Educação Nacional (LDB): artigo $3^{\circ}$ : como princípios da educação, dentre outros, a liberdade de ensinar, pesquisar e divulgar o pensamento e o saber; o pluralismo, não só de concepções pedagógicas, mas de ideias; o respeito à liberdade e à tolerância; a vinculação entre a educação e as práticas sociais; a consideração com a diversidade étnico-racial.

c) Por normas de planejamento, instituídas pelo Plano Nacional de Educação (PNE): qual devem ser estabelecidas as metas e estratégias a serem alcança - das em um determinado espaço de tempo, em cumprimento à CF e à LDB; e pelo Conselho Nacional de Educação (CNE) e dos Conselhos Estaduais de Educação (CEEs), vinculado ao Ministério da Educação (MEC) (RODRIGUES, 2014).

$\mathrm{Na}$ esfera das instituições de ensino superior, tem-se a competência de executar as Normas Gerais da Educação Nacional e ao PNE, cumprindo a exigência constitucional de manutenção e elevação de qualidade e de formular normas de planejamento para cumprir tal meta, as quais estarão contidas (a) no Plano de Desenvolvimento Institucional (PDI), que deve conter os objetivos e estratégias para um período de 5 anos; e (b) no Projeto Pedagógico Institucional (PPI) (RODRIGUES, 2014).

Aos diversos cursos de cada IES, compete-lhes estruturar seus Projetos Pedagógicos de Cursos (PPCs), que deverão conter a clara concepção do curso, suas peculiaridades, seu currículo pleno e sua operacionalização. Além disso, há o Currículo do Curso, que estabelece as suas disciplinas, obrigatórias e optativas, determinando as ementas. Finalmente, ao docente, cabe-lhe respeitar todas essas diretrizes e, ainda, projetar o Plano de Ensino e o Plano de Aula em consonância com tais diretrizes (RODRIGUES, 2014).

Desse espectro, deduz-se que a atuação do docente é de caráter institucional, situado a partir de um conjunto de competências, deveres e direitos os quais representam uma relação jurídica profissional e uma relação interpessoal. Como atividade 
institucionalizada, portanto, devem ser cumpridas as funções determinadas, respeitadas as normas institucionais, cumpridas as atribuições e observado o projeto pedagógico, além de o respeito pautar as relações pessoais e institucionais. Nesse sentido, cada instituição de ensino, seja pública ou privada, possui um conjunto disciplinar de direitos e deveres que se insere nesse quadro normativo de como deve ser a atuação do profissional.

Além disso, a liberdade de ensinar é orientada pelo direito do educando de aprender, esse direito é balizado pelo seu desenvolvimento enquanto ser humano livre, participante da vida coletiva, em consonância com a garantia da dignidade humana.

Em tal cenário, importante ressaltar que são variadas as abordagens de ensino que podem ser adotadas pelo professor em sua atuação, das quais se mencionam cinco (MIZUKAMI, 1996):

a) Tradicional, que se fundamenta na prática educativa e na transmissão através dos anos, privilegiando-se o especialista, os modelos e o professor na ideia de que o papel do professor se caracteriza pela garantia de que o conhecimento seja conseguido independentemente do interesse e da vontade do aluno. $\mathrm{O}$ aluno é considerado um receptor passivo até que, repleto das informações necessárias, pode repeti-las a outros que ainda não as possuam - perspectiva que é advindo da psicologia sensual-empirista, do ensino verbalista da Idade Média e Renascença e defendido nos séculos XVIII e XI. A interação professor-aluno é vertical, em que o professor detém o poder decisório quando à metodologia, conteúdo, avaliação, forma de interação, etc. e, em um formato mais extremado, as relações sociais são quase que praticamente suprimidas e a classe, como consequência, permanece intelectual e afetivamente dependente do professor.

b) Comportamentalista, inspirada em Skinner, em que se defende que o conhecimento é uma descoberta, apesar de já se encontrar presente na realidade exterior, tanto a ciência quanto o comportamento são considerados como uma forma de conhecer os eventos, o que torna possível a sua utilização e o seu controle. Os modelos são desenvolvidos a partir da análise dos processos por meio dos quais o comportamento é modelado e reforçado. Recompensa e controle, planejamento cuidadoso das contingências de aprendizagem, das sequelas de atividades de aprendizagem, modelagem do comportamento humano, a partir da manipulação de reforços, desprezando os elementos não observáveis ou subjacentes a este mesmo comportamento. Assim, o ensino é comporto 
por padrões de comportamento que podem ser mudados através do treinamento, segundo objetivos pré-estabelecidos.

c) Humanista, com referências teóricas em Neil e Carl Rogers. Em tal abordagem, o enfoque é no sujeito, em que o sujeito é o principal elaborador do conhecimento humano. A ênfase é sobre as relações interpessoais e ao crescimento que delas resulta, centrado no desenvolvimento da personalidade do indivíduo, em seus processos de construção e organização pessoal da realidade, e em sua capacidade de atuar, como uma pessoa integrada. Dá-se primazia à vida psicológica e emocional do indivíduo e à preocupação com a sua orientação interna, com o autoconceito, com o desenvolvimento de uma visão autêntica de si mesmo, orientada para a realidade individual e grupal. Desse modo, o professor não transmite o conteúdo, dá assistência, sendo um facilitador da aprendizagem. Assim, tem-se que a experiência pessoal e subjetiva é o fundamento sobre o qual o conhecimento abstrato é construído, não havendo modelos prontos, mas processo de vir-a-ser.

d) Cognivitista, com bases nas teorias de Piaget e Bruner, em que o ensino é considerado mais do que um produto do ambiente, das pessoas ou de fatores que são externos ao aluno. É dada ênfase em processos cognitivos e na investigação separada dos problemas sociais contemporâneos, com as emoções articuladas. O aluno e seu meio são analisados conjuntamente, já que o conhecimento é o produto da interação entre sujeito e objeto, não se enfatizando polo nenhum da relação. Nessa perspectiva, o indivíduo é um sistema aberto, em reestruturações sucessivas, em busca de um estágio final nunca alcançado por completo. O desenvolvimento do ser humano consiste, de forma genérica, em se alcançar o máximo de operacionalidade em suas atividades, motoras, verbais ou mentais. Assim, caberá ao professor criais situações, propiciando condições onde possam se estabelecer reciprocidade intelectual e cooperação ao mesmo tempo moral e racional.

e) Sócio-cultural, em que se prima pela atenção à cultura popular e tem-se, como referência, Paulo Freire. É considerada uma síntese de tendências como: neotomismo, humanismo, fenomenologia, existencialismo e neomarxismo. O foco, então, é criar condições para que os indivíduos assumam os valores, e não só os consumam. Para tanto, relação professor-aluno é horizontal e o professor deve estar engajado numa prática transformadora procurará desmitificar e questionar, com o aluno, a cultura dominante, valorizando a linguagem e a cultura deste, criando condições para que cada um deles analise seu contexto e produza cultura. Logo, Haverá preocupação com cada aluno em si, 
com o processo e não com produtos de aprendizagem acadêmica padronizado. Assim, o diálogo é desenvolvido, ao mesmo tempo em que são oportunizadas a cooperação, a união, a organização, a solução em comum dos problemas.

Nesse contexto pedagógico-jurídico, a inclusão de mais uma normativa jurídica, a qual deve seguida pelo professor, é a proposta do Programa Escola Sem Partido, o qual se examina analítico e objetivamente a seguir.

\section{EXAME OBJETIVO DO PROGRAMA ESCOLA SEM PARTIDO}

Em tal tópico, pretende-se identificar as categorias essenciais do Programa Sem Partido para compreender o seu delineamento legislativo. Assim, questionam-se: (a) sobre a definição; (b) sobre as pessoas envolvidas diretamente; (c) sobre as normas específicas destinadas aos professores; (d) sobre a motivação da proposta de lei; (e) sobre a causa do programa.

De plano, portanto, o Programa Sem Partido é um projeto de lei, autuado sob $\mathrm{n}^{\mathrm{o}}$ 193/2016, que pretende incluir nas diretrizes e bases da educação nacional determinados dispositivos legais.

As pessoas envolvidas diretamente nos dispositivos legais são os professores, os alunos e os pais ou responsáveis dos alunos. Pela leitura da proposta de lei, verifica-se que há limitação à prática de docência, visando à observância do "direito de aprender" e ao "direito dos pais a que seus filhos recebam a educação moral que esteja de acordo com suas próprias convicções" (art. 5º inciso V).

Aqui, importante uma dedução: por mais que nas entrevistas de Miguel Nagib da legislativa haja o destaque de que não há limitação à atuação do professor (NAGIB, 2016), é claro que há vedação de que sejam referidos assuntos como a teoria de gênero e a nítida orientação de que as convicções e crenças dos pais e responsáveis devem ser respeitadas (art. $5^{\circ}$, inciso $\mathrm{V}$ do projeto). Somente aí já se verifica a restrição à atuação docente.

Além disso, é importante destacar que, no ordenamento jurídico pátrio, não há correspondência de um "direito dos pais", em tal concepção ${ }^{5}$. Assim, tal proposta ainda detém o condão de criar esse instituto.

\footnotetext{
${ }^{5}$ Segundo o parágrafo único do art. 53 do Estatuto da Criança e do Adolescente (Lei no 8.069/1990), é direito dos pais ou responsáveis ter ciência do processo pedagógico, bem como participar da definição das propostas
} 
$\mathrm{O}$ art. $5^{\circ}$ do projeto traz qual deve ser o comportamento do professor, o que responde a questão do item "c":

\begin{abstract}
Art. $5^{\circ}$. No exercício de suas funções, o professor: I - não se aproveitará da audiência cativa dos alunos, para promover os seus próprios interesses, opiniões, concepções ou preferências ideológicas, religiosas, morais, políticas e partidárias ; II - não favorecerá nem prejudicará ou constrangerá os alunos em razão de suas convicções políticas, ideológicas, morais ou religiosas, ou da falta delas; III - não fará propaganda político partidária em sala de aula nem incitará seus alunos a participar de manifestações, atos públicos e passeatas; IV - ao tratar de questões políticas, socioculturais e econômicas, apresentará aos alunos, de forma justa, as principais versões, teorias, opiniões e perspectivas concorrentes a respeito; V - respeitará o direito dos pais dos alunos a que seus filhos recebam a educação religiosa e moral que esteja de acordo com as suas próprias convicções; VI - não permitirá que os direitos assegurados nos itens anteriores sejam violados pela ação de estudantes ou terceiros, dentro da sala de aula.
\end{abstract}

Nesse tal conteúdo, é importante destacar que o docente que assim age já desrespeita a sua atuação e recebe sanção de acordo com as normas institucionais. As considerações detalhadas sobre tal dispositivo serão feitas no tópico seguinte.

O motivo e a causa para a proposta do Programa ESP são encontrados no documento que o acompanha, intitulado "Justificativa". Nele, diz-se que o projeto de lei tem como objetivo "vedar práticas ilícitas, violadoras de direitos e liberdades fundamentais dos estudantes e de seus pais ou responsáveis". E a justificativa para tanto são dois argumentos. O primeiro é que

É fato notório que professores e autores de materiais didáticos vêm se utilizando de suas aulas e de suas obras para tentar obter adesão dos estudantes à determinadas correntes políticas e ideológicas para fazer com que eles adotem padrões de julgamento e de conduta moral - especialmente moral sexual - incompatíveis com os que lhes são ensinados por seus pais ou responsáveis.

educacionais. Além disso, no corpo do dispositivo: "A criança e o adolescente têm direito à educação, visando ao pleno desenvolvimento de sua pessoa, preparo para o exercício da cidadania e qualificação para o trabalho, assegurando-se-lhes: I - igualdade de condições para o acesso e permanência na escola; II - direito de ser respeitado por seus educadores; III - direito de contestar critérios avaliativos, podendo recorrer às instâncias escolares superiores; IV - direito de organização e participação em entidades estudantis; V - acesso à escola pública e gratuita próxima de sua residência". 
O segundo, expressa que:

Diante dessa realidade - reconhecida por experiência direta de todos os que passaram pelo sistema de ensino nos últimos 20 ou 30 anos -, entendemos que é necessário e urgente adotar medidas eficazes para prevenir a prática de doutrinação política e ideológica nas escolas, e a usurpação do direito dos pais a que seus filhos recebam a educação moral que esteja de acordo com suas próprias convicções.

A partir desse exame objetivo, traçam-se, nos itens que seguem, apontamentos sobre as concepções jurídicas trazidas pela lei e sobre a pertinência jurídica e motivacional do programa.

\section{CONCEPÇÕES ABERTAS DOS DISPOSITIVOS TRAZIDOS PELO PROGRAMA ESP}

$\mathrm{Na}$ análise das concepções trazidas pelo Programa, destacam-se dois dispositivos: o $\operatorname{art.} 2^{\circ}$ e o art. $5^{\circ}$.

$\mathrm{O}$ art. $2^{\circ}$ estabelece, em seus incisos, os princípios que deverão ser atendidos na educação nacional: neutralidade política, ideológica e religiosa do Estado; pluralismo de ideias no ambiente acadêmico; liberdade de aprender e de ensinar; liberdade de consciência e de crença; reconhecimento da vulnerabilidade do educando como parte mais fraca na relação de aprendizado; educação e informação do estudante quanto aos direitos compreendidos em sua liberdade de consciência e de crença; direito dos pais a que seus filhos recebam a educação religiosa e moral que esteja de acordo com as suas próprias convicções.

O princípio da neutralidade política, ideológica e religiosa do Estado, não encontrado em outra disposição legal no ordenamento jurídico brasileiro, traz uma série de questionamentos basilares sobre a definição de tal neutralidade, qualificada política, ideológica e religiosamente. Isso porque é necessário, também, trazer a conceituação do que é política, ideologia e religião. 
$\mathrm{Na}$ perspectiva de Hannah Arendt ${ }^{6}$, por exemplo, política caracteriza o convívio entre as pessoas; logo, inviável a dúbia neutralidade neste caso. Além disso, até mesmo a Constituição Federal impõe-se como um projeto político à sociedade brasileira ao prever a educação visa ao desenvolvimento pleno da pessoa, a qualificação para o trabalho e o preparo para o exercício da cidadania, em respeito à diversidade - como recomendar tal neutralidade ou cumpri-la?

No que se refere à ideologia, pode-se contemplá-la como um pensamento que confere alienação a seus receptores; ou como o sentido que se dá a determinados eventos (CHAUÍ, 2000). E, no que se refere à religião: dependendo de qual concepção se trata, pode-se estar vedando um tratamento ético pautado pela não-violência - como deve o professor se eximir de tal postura?

Em seguida, o pluralismo de ideias no ambiente acadêmico é princípio encontrado no art. 206, III, da Constituição Federal, mas seguido da expressão concepções pedagógicas. Assim, o pluralismo de ideias é associado, constitucionalmente ao pluralismo de concepções pedagógicas, com os exemplos mencionados na segunda parte deste trabalho.

A liberdade de aprender e de ensinar não é princípio restrito a tais ações. Essa liberdade é também seguida constitucionalmente pela expressão pesquisar e divulgar o pensamento, a arte e o saber. Assim, pelo art. 206, II, tem-se reconhecida a liberdade de aprender, ensinar, pesquisar e divulgar o pensamento, a arte e o saber.

$\mathrm{Na}$ sequência, o princípio do reconhecimento da vulnerabilidade do educando como parte mais fraca na relação de aprendizado também se traduz em inovação legislativa, eis que inexistente nos dispositivos legais vigentes. Tal princípio tem, em seu bojo, o questionamento do que caracterizaria a mencionada vulnerabilidade e a condição do estudante como parte mais fraca. Diferentemente do Estatuto da Criança e Adolescente, que reconhece a condição peculiar da criança e do adolescente como pessoas em desenvolvimento (art. $6^{\circ}$ ), tal dispositivo promove a hierarquia entre educandos de maneira geral (aí sem a diferenciação de capazes ou incapazes), posicionando-os em uma categoria mais fraca na relação de aprendizado. Além disso, tais inquietações são trazidas em reconhecimento às várias abordagens do processo de ensino: vê-se que o projeto disciplina diretrizes focadas em um processo tradicional, em que o aluno é considerado uma

\footnotetext{
${ }^{6}$ De tal forma, a política é baseada na pluralidade dos homens, tratando-se da convivência entre diferentes, respeitando-se a sua coexistência. Cf. ARENDT, 1998.
} 
audiência cativa e o professor, o modelo a ser seguido. Assim, todavia, desconsideram-se as possibilidades de interação de ensino havidas entre as partes, bem como o pluralismo de concepções pedagógicas.

Ao princípio da educação e informação do estudante quanto aos direitos compreendidos em sua liberdade de consciência e de crença não se tece qualquer comentário, visto que é direito fundamental previsto constitucionalmente.

Finalmente, o último inciso traz uma inovação jurídica, que seria "o direito dos pais a que seus filhos recebam a educação religiosa e moral que esteja de acordo com as suas próprias convicções”, disciplinando que a atuação do docente deve se adequar à religião e à moral defendida pelos pais ou responsáveis do educando - cujo cumprimento, em um ambiente plural, é inviável.

No parágrafo único do art. $2^{\circ}$, ainda, há a seguinte proposta de determinação:

O Poder Público não se imiscuirá na opção sexual dos alunos nem permitirá qualquer prática capaz de comprometer, precipitar ou direcionar o natural amadurecimento e desenvolvimento de sua personalidade, em harmonia com a respectiva identidade biológica de sexo, sendo vedada, especialmente, a aplicação dos postulados da teoria ou ideologia de gênero.

No dispositivo, é solar a vedação às referências à teoria de gênero, que é atualmente sustentada pelo Plano Nacional de Direitos Humanos (Decreto $\mathrm{n}^{\mathbf{0}} 7.037$, de 21 de dezembro de 2009) e o Decreto $n^{\circ} 8.727$, de 28 de abril de 2016, que disciplina a utilização do nome social na esfera federal ${ }^{7}$.

Além disso, há o equívoco no termo opção sexual, visto que o comportamento afetivo entre as pessoas não é uma preferência ou escolha, mas sim uma orientação ou condição - assim, o termo correto é condição ou orientação afetivo-sexual.

Ainda, com a vedação à referência da teoria de gênero, há a indicação de que identidade biológica de sexo deve ser respeitada, em que se pretende normatizar

\footnotetext{
${ }^{7}$ O Decreto traz definições relevantes no parágrafo único do art. $1^{\text {o: }}$ "Para os fins deste Decreto, considera-se: I - nome social - designação pela qual a pessoa travesti ou transexual se identifica e é socialmente reconhecida; e II - identidade de gênero - dimensão da identidade de uma pessoa que diz respeito à forma como se relaciona com as representações de masculinidade e feminilidade e como isso se traduz em sua prática social, sem guardar relação necessária com o sexo atribuído no nascimento".
} 
juridicamente a cisgeneridade - o que não é determinado pela nossa legislação atual. Assim, seria a transgeneridade uma transgressão legal ${ }^{8}$.

No art. $5^{\circ}$ do Programa ESP, por sua vez, há a determinação de que o professor (a) não se aproveitará da audiência cativa dos alunos, para promover os seus próprios interesses, opiniões, concepções ou preferências ideológicas, religiosas, morais, políticas e partidárias; (b) não favorecerá nem prejudicará ou constrangerá os alunos em razão de suas convicções políticas, ideológicas, morais ou religiosas, ou da falta delas; (c) não fará propaganda político - partidária em sala de aula nem incitará seus alunos a participar de manifestações, atos públicos e passeatas; (d) ao tratar de questões políticas, socioculturais e econômicas, apresentará aos alunos, de forma justa, as principais versões, teorias, opiniões e perspectivas concorrentes a respeito; (e) respeitará o direito dos pais dos alunos a que seus filhos recebam a educação religiosa e moral que esteja de acordo com as suas próprias convicções; (f) não permitirá que os direitos assegurados nos itens anteriores sejam violados pela ação de estudantes ou terceiros, dentro da sala de aula.

Com relação aos itens $\mathrm{b}$ e $\mathrm{f}$, não se fará, aqui, considerações sobre tais determinações, visto que se tratam de conduta ética a ser tomada pelo professor, o qual, se em postura transgressora, deve ser penalizado, conforme as normas institucionais. Sobre isso, importa destacar que, com a existência de tais normas já vigentes, faz-se desnecessária a propositura de sua repetição. Ainda, em referência ao item e, prescindível a reiteração de seu exame, eis que já feito anteriormente.

No item a, então, urge se questionar o que seria a "audiência cativa dos alunos", bem como o que caracterizaria a "promoção de seus próprios interesses". Na primeira expressão, vê-se claramente a imposição de uma abordagem tradicional de ensino, estagnada na concepção da Idade Média. Já a promoção dos próprios interesses é uma expressão em que comporta diversas ações, o que gera ambiguidade no caso de sua aplicação.

Sobre o item c, importa destacar que, na fala de Miguel Nagib, na entrevista já referida, relatou que, na época das passeatas contra o Governo Collor, haviam milhares de estudantes nas ruas, com caras pintadas; contudo, na época atual, foram poucos os

\footnotetext{
${ }^{8}$ A cisgeneridade representa A qualificação das pessoas que foram designadas com um gênero (feminino ou masculino) ao nascer e se identificam com ele. A transgeneridade, por sua vez, como a qualificação das pessoas que foram designadas com um gênero a nascer e não se identificam com ele. Ressalta-se que, aqui, não se abordam as pretensões de existência dos gêneros além do binarismo feminino-masculino.
} 
estudantes às ruas se posicionar contra o Governo Dilma, em 2016. Em tal comparação, o advogado faz uma causalidade direta dos momentos, como se não houvesse outro fator preponderante que influenciasse na participação dos estudantes nas movimentações deste ano. Assim, apresenta tal argumento como fonte motivadora para afirmar o encampamento do ensino brasileiro por partidos de base esquerdista. É o que justificaria, falaciosamente, tal inciso.

O inciso seguinte determina que as questões a serem apresentadas em sala de aula devem ser expostas de forma justa. Aqui, portanto, outra expressão dúbia: o que seria $a$ forma justa adequada para expor determinadas questões aos alunos.

Termos e expressões de concepção aberta, a serem interpretadas, no caso em concreto, por magistrado, devem ser pensadas de acordo com o contexto sistemático da lei. Nesse compasso, é cediço que a proposta de inovação legislativa restringe-se ao texto apresentado no projeto; no entanto, é importante analisar, como já mencionado, a justificativa de tal proposta, pois imprescindível à interpretação histórica da lei, bem como as colocações presentes no movimento parlamentar que apoia o referido programa. Assim, nota-se que no site do movimento (EscolaSemPartido.Org), há explicação, para preenchimento semântico das expressões dúbias, o que seria um professor doutrinador, entre outras (NAGIB et al, 2016):

Você pode estar sendo vítima de doutrinação ideológica quando seu professor:

- se desvia frequentemente da matéria objeto da disciplina para assuntos relacionados ao noticiário político ou internacional;

- adota ou indica livros, publicações e autores identificados com determinada corrente ideológica;

- omite ou minimiza fatos desabonadores à corrente políticoideológica de sua preferência;

- não admite a mera possibilidade de que o "outro lado" possa ter alguma razão.

Diante disso, verificada a insegurança jurídica pela abertura semântica das concepções jurídicas propostas pelo projeto de lei e pela clareza quanto à restrição da atuação do docente, passa-se à verificação da pertinência jurídica e motivacional do programa. 


\section{VERIFICAÇÃO DA PERTINÊNCIA JURÍDICA DO PROGRAMA ESP: O CRITÉRIO DA PROPORCIONALIDADE E O CONTROLE DE EVIDÊNCIA E JUSTIFICABILIDADE APLICADOS NO SUPREMO TRIBUNAL FEDERAL}

Inicialmente, verificam-se os principais argumentos que visam justificar o Programa ESP.

Aqui, portanto, importa ressaltar que os parlamentares defensores do projeto alegam que não há inovação legislativa com o Programa ESP, visto que tais deveres já existem na própria Constituição e, ainda, que há o aparelhamento do sistema educacional por determinadas correntes partidárias (NAGIB, 2016). Pois bem. Já nesse ponto se questiona a necessidade da lei: ora, se tal regulamentação já existe, não há necessidade de outra norma que discipline exatamente a mesma conduta.

Além de tal desnecessidade normativa da lei, os motivos que a embasam, quais sejam (a) o fato notório sobre a má utilização de aulas e de livros para obter adesão dos alunos, especialmente com relação a padrões de julgamento moral sexual questionáveis e (b) a realidade conhecida por todos que passaram por experiência direta no sistema de ensino, são argumentos frágeis demais, que não se embasam em nenhuma pesquisa - o que poderia caracterizar o argumento como forte, eis que pautado em dados objetivos. $\mathrm{O}$ argumento é fraco, e mais, é subjetivo. Tenta-se conferir objetividade ao argumento sustentando que é uma "realidade conhecida por todos", o que prejudica ainda mais a proposição em razão da abertura questionável da expressão: quem somos esses todos?

Diante da argumentação trazida em uma tentativa de respaldar o projeto, verifica-se essa fragilidade mencionada e também a contradição da afirmativa de que o Programa ESP não criaria novos deveres, o que se percebe facilmente da leitura dos dispositivos propostos que é um equívoco. Com o delineamento jurídico do programa, vê-se a restrição ao exercício da profissão da docência, ao que seria fundamentado para se proteger um bem fundamental, que é o direito à educação.

Passando-se, então, a uma análise da restrição de um direito frente ao objetivo de proteção a um bem fundamental, que é o direito à educação, orienta-se pelo critério da proporcionalidade, teorizado por Robert Alexy.

Aqui, explica-se que, quando se fala em imposição de uma medida estatal que restrinja alguma liberdade, logo me vem uma forma de verificar a convergência jurídica e 
política de tal medida, que é a regra da proporcionalidade, formada por três sub-regras, que são a adequação, a necessidade e a proporcionalidade em sentido estrito.

Ao se analisar a adequação, questiona-se se limitar a atuação do professor em sala de aula é medida suficiente para garantir o direito à educação? É suficiente para garantir a suposta ausência de doutrinação? Quando se verifica a necessidade, pergunta-se se é necessária tal medida? Não há outra forma para que se garanta o direito à educação? Ou não há outra forma para que se garanta a não-doutrinação? Por sua vez, ao se examinar a a proporcionalidade em sentido estrito, verifica-se a tensão entre a intensidade da restrição ao direito e a importância da realização do direito fundamental. Assim, basta que os motivos que fundamentam a adoção da medida não tenham peso suficiente para justificar a restrição ao direito fundamental atingido. Nesse sentido, se a importância da realização do direito fundamental, no qual a limitação se baseia, não for suficiente para justificá-la, a medida será considerada desproporcional.

Para a análise do projeto em referência, verifica-se a adequação questionando se, em linhas gerais (e não em hipóteses ventiladas pelos parlamentares, que não possuem a veracidade da generalização) a restrição à atuação docente é suficiente para se garantir o direito à educação. À resposta de tal inquietude, alega-se que o direito à educação é diretamente proporcional à diversidade da atuação docente. Assim, havendo uma restrição à atividade do professor, consequentemente, há a restrição da educação do aluno. Assim, já se pode inferir que o projeto de lei é inadequado, o que redundaria na conclusão de que não possui pertinência argumentativa 9 .

Em tal análise, orienta Robert Alexy que a restrição verificada já não se sustenta e, por isso, prescinde-se da verificação das demais sub-regras. No entanto, para fins acadêmicos, segue-se ao exame.

Ao se questionar sobre a necessidade da proposta legislativa, examina-se se não há outros meios pelos quais o direito à educação receba a proteção que os parlamentares pretendem. A resposta é sim: a proteção à educação dá-se, exatamente, com a diversidade das temáticas articuladas em sala de aula (e não com a restrição da atividade docente), bem como com as normativas já existentes sobre a conduta ética a qual deve pautar o trabalho do professor. Logo, tal proposta também é desnecessária.

\footnotetext{
${ }^{9}$ A conclusão a ser conferida, igualmente, é a de que o projeto é inconstitucional.
} 
Por fim, em análise à proporcionalidade em sentido estrito, perquire-se sobre a justificativa da restrição da atividade docente em sopesamento com a importância da realização do direito fundamental à educação. De plano, tem-se como inquestionável a importância da concretização do direito à educação; contudo, tal análise deve ser aliada à justificativa de restrição da atuação profissional referida. Verifica-se, então, que, nem na justificativa da lei, nem na fala de parlamentares defensores do projeto (especialmente, de seu proponente, de que se poderia extrair argumentos mais fortes), não existe nenhum estudo ou fonte confiável para embasar a restrição profissional. Por isso, tem-se como desproporcional o Programa ESP.

É possível, ainda, analisar a pertinência jurídica e argumentativa do projeto de lei a partir do controle sobre a idoneidade da medida restritiva aplicado no Supremo Tribunal Federal e em outros países.

Em determinada decisão, o Min. Gilmar Mendes apresentou a verificação da pertinência mencionada no Recurso Extraordinário (RE) 635659. Também adotada pelo Tribunal Constitucional Alemão, esse controle constitui-se com duas faces: o controle de evidência e o controle de justificabilidade.

O controle de evidência representa a verificação se as medidas adotadas pelo legislador mostram-se idôneas à efetiva proteção do bem jurídico fundamental Assim, em um primeiro nível, deve-se reconhecer ao legislador uma ampla margem de avaliação, valoração e conformação quando às medidas que reputar adequadas e necessárias. A norma somente poderá ser declarada inconstitucional quando as medidas adotadas pelo legislador se mostrarem claramente inidôneas para a efetiva proteção do bem jurídico.

O controle de justificabilidade analisa se a decisão legislativa foi tomada após apreciação objetiva e justificável das fontes de conhecimento então disponíveis. É o segundo nível do exame, em que tal controle está orientado a verificar se a decisão legislativa foi tomada após uma apreciação objetiva e justificável de todas as fontes de conhecimento então disponíveis. Verifica-se se o legislador levantou e considerou, diligente e suficientemente, todas as informações disponíveis, e se realizou prognósticos sobre as consequências da aplicação da norma. Enfim, se o legislador valeu-se de sua margem de ação de maneira sustentável.

Especificadamente, o controle de evidência tangencia o conteúdo da adequação, conforme explicitado acima e, ainda, conforme já analisado, tem-se a insuficiência da restrição para se salvaguardar o direito à educação. Já o controle de justificabilidade, por 
sua vez, pode ser equiparado à análise da justificativa necessária na terceira sub-regra explanada acima, que é a proporcionalidade em sentido estrito. Aqui, então, tem-se que não houve nenhum levantamento ou consideração, diligente e suficiente, todas as informações disponíveis, sobre a temática, bem como não se realizou nenhum prognóstico sobre as consequências da aplicação da norma. Aqui, portanto, vê-se que a decisão legislativa para a propositura do projeto não é justificável, pois não fez nenhum apreciação das fontes de conhecimento relativas à temática.

Ademais, afastar dos alunos e as alunas do acesso de dados e informações que divirjam dos seus paradigmas morais e religiosos não se caracteriza, de modo algum, como uma tutela ao direito à educação, nem mesmo uma proteção contra uma suposta doutrinação (CAMBI; ZANINELLI, 2014). Evitar o acesso a informações viola, sim, o direito de aprender de educandos e obsta uma forma de se concretizar a possibilidade de tornarem-se pessoas conscientes e críticos, que é o fim da educação.

\section{CONSIDERAÇÕES FINAIS}

Diante do exposto, e ao contrário do defendido acerca do Programa Escola Sem Partido, é nítida a proposta de inovação jurídica para a criação de restrições à atividade docente e, também, apresenta termos e expressões cujo conteúdo são amplamente questionáveis, acarretando em uma insegurança jurídica para sua aplicação. Em tal ponto, importante questionar sobre a nomenclatura "Escola Sem Partido", visto que (a) não existe "Escola Com Partido" e (b) o projeto de lei é muito limitado ao se referir a conotações partidárias - mas rico na relação sobre determinada conduta moral a ser adotada pelos professores.

Nesse sentido, o projeto de lei perfaz-se como contraditório, pois prega uma suposta neutralidade ao mesmo tempo em que veda a fala de assuntos e orienta que a atuação deve se guiar pelas convicções religiosas e morais dos pais. Nessa específica proposta de restrição, ainda, o texto legislativo expressa a confusão entre a esfera pública e esfera privada, ao trazer as convicções dos pais como necessárias à educação formal do estudante. 
Além disso, o motivo do programa não é devidamente justificada, pois apresenta argumentação fraca, desprovida de elementos objetivos suficientes para uma motivação legislativa.

Numa perspectiva de proporcionalidade para a restrição da atividade docente, é inadequada, pois não tem aptidão para alcançar o objetivo (proteção da educação); é desnecessária, pois há outras formas de se coibir suposta doutrinação e de proteger a educação; e não são justificáveis tais restrições porque, na medida em que se cala o professor, se limita o aluno em determinado assunto e, ainda, não apresenta motivação suficiente - sequer apresenta argumentação objetiva.

Além disso, em um controle de evidência: não é idônea para garantir uma educação de qualidade; e em um controle de justificabilidade, vê-se que tal lei não foi formatada após uma apreciação objetiva e justificável de todas a fontes de conhecimento disponíveis. Não houve levantamento,, diligente e suficiente, das informações disponíveis sobre o tema, e não se realizou prognósticos sobre as consequências da aplicação da norma.

Diante disso, por fim, tem-se que o Programa Escola sem Partido justifica-se não na proteção ao direito de aprender, ao direito à educação, mas no estabelecimento de determinadas condutas que, com cunho ideológico, restringem a liberdade de atuação docente e, consequentemente, o direito de aprender da estudante e do estudante, em movimento contrário à própria proposta do programa.

\section{REFERÊNCIAS BIBLIOGRÁFICAS}

ARENDT, Hannah. O que é política? Rio de Janeiro: Bertrand Brasil, 1998.

BRASIL. Constituição (1988). Constituição da República Federativa do Brasil: promulgada em 5 de outubro de 1988. Organização do texto: Juarez de Oliveira. 4. ed. São Paulo: Saraiva, 1990. 168 p. (Série Legislação Brasileira).

BRASIL. Disposições sobre o uso do nome social e sua aplicação na Administração Pública (2016). Decreto $\mathrm{n}^{\mathrm{o}}$ 8.727, de 28 de abril de 2016. Disponível em < http://www.planalto.gov.br/ccivil_03/_Ato2015-2018/2016/Decreto/D8727.htm>. Acesso em 05 ago 2016.

BRASIL. Estatuto da Criança e do Adolescente (1990). Lei n ${ }^{\circ}$ 8.069, de 1990. Disponível em < http://www.planalto.gov.br/ccivil_03/leis/L8069Compilado.htm>. Acesso em 05 ago 2016. 
BRASIL. Lei de Diretrizes e Bases da Educação Nacional (1996). Lei 9.394/1996. Disponível em < http://www.planalto.gov.br/ccivil_03/leis/L9394.htm>. Acesso em 05 ago 2016.

BRASIL. Plano Nacional de Direitos Humanos (2009). Decreto $\mathrm{n}^{\circ}$ 7.037, de 21 de dezembro de 2009. Disponível em < http://www.planalto.gov.br/ccivil_03/_Ato20072010/2009/Decreto/D7037.htm>. Acesso em 05 ago 2016.

BRASIL. Supremo Tribunal Federal. Exame da constitucionalidade do art. 28 da Lei $\mathrm{n}^{\circ}$ 11.343/2006, que criminaliza o porte de drogas para consumo pessoal, restringindo seu voto à maconha, droga apreendida com o autor do recurso. Decisão do Relator no Recurso Extraordinário (RE) 635659. Relator: Ministro Gilmar Mendes. DJE n ${ }^{\circ}$ 39, divulgado em 01/03/2016.

CAMBI, Eduardo; ZANINELLI, Giovana. Direito fundamental à educação, exclusão social e cidadania. Revista de Direito Privado, v. 59, p. 29-54, jul./set. 2014, p. 13.

CHAUÍ, Marilena. Filosofia. São Paulo: Ática, 2000.

MIZUKAMI, Maria da Graça Nicoletti. Ensino: as abordagens do processo. São Paulo: EPU, 1986.

NAGIB, Miguel, et al. Flagrando o doutrinador. Disponível em < http://escolasempartido.org/flagrando-o-doutrinador>. Acesso em 10 ago 2016.

NAGIB, Miguel. Escola Sem Partido. Disponível em <https://www.youtube.com/watch?v=J2v7PA1RNqk>. Entrevista concedida ao Canal Futura pelo Programa Sala Debate, publicado em 19 de julho de 2016.

RODRIGUES, Horácio Wanderlei. Planejando atividades de ensino-aprendizagem para cursos de direito. In RODRIGUES, Horácio Wanderlei; ARRUDA JUNIOR, Edmundo Lima de (org.). Educação jurídica. 3. ed. v. II. Florianópolis, 2014.

RODRIGUES, Horácio Wanderlei; ARRUDA JUNIOR, Edmundo Lima de (org.). Educação jurídica. 3. ed. v. II. Florianópolis, 2014. 